\section{Uso de enzimas como tratamiento dermatológico regenerador de las líneas de expresión}

\section{Use of enzymes as a regenerative dermatological treatment of expression lines}

\section{Uso de enzimas como tratamento dermatológico regenerativo de linhas de expressão}

\author{
Zulay M Rivera P. \\ jimenavillca@hotmail.com
}

Recibido diciembre 2019 / Revisión enero 2020 / Aceptado 1 de mayo 2020

\begin{abstract}
RESUMEN
Introducción: El tratamiento con enzimas es una alternativa estética mínimamente invasiva para mejorar la apariencia facial y disminuir las líneas de expresión. Objetivo: Determinar el uso de las enzimas hialuronidasa, colagenasa y lipasa como tratamiento enzimático dermatológico para las líneas de expresión facial. Materiales y método: Estudio de campo, prospectivo, población 457 pacientes que acudieron a la consulta dermatológica entre los años 2013 y 2018 para tratamiento con enzimas. El instrumento de recolección de datos fue la hoja de registro y la fuente documental las historias clínicas. El método estadístico fue descriptivo, la información se presenta en tablas y gráficos. Resultados: La edad promedio de los pacientes fue de 45,2 $\pm 10,1$ años, $40,9 \%$ recibió 2 kits de enzimas con los 3 componentes básicos de colagenasa, hialuronidasas y lipasas. Se encontró diferencia significativa en la relación de atención entre hombres y mujeres, de 1:14, es decir las mujeres acudieron más a la consulta solicitando la colocación de este tratamiento. Conclusión: El tratamiento con enzimas aporta beneficios al incrementar la permeabilidad dérmica, aumenta el flujo sanguíneo y el drenaje linfático, disminuye los tabiques fibrosos de la celulitis, la flacidez, adiposidades, y rejuvenece el aspecto general. Por lo que se plantea como un tratamiento efectivo para disminuir las líneas de expresión.
\end{abstract}

Palabras clave: Enzimas, tratamiento, colagenasa, hialuronidasas y lipasas

\begin{abstract}
Introduction: Enzyme treatment represents a minimally invasive aesthetic alternative to improve facial appearance and decrease expression lines. Objective: To determine the use of the enzymes hyaluronidase, collagenase and lipase as a dermatological enzyme treatment as a regenerative treatment for expression lines. Methods: A prospective field study was conducted of a population made up of 457 patients who attended the UNIMEL dermatological consultation between 2013 and 2018 to be treated with enzymes. The data collection instrument was the record sheet and the documentary source was the medical records. The statistical method was descriptive, the information is presented in tables and graphs. Results: the average age was $45.2 \pm 10.1$ years of age, to whom a majority of $40.9 \%$ were applied 2 kits of enzymes with the 3 basic components of collagenase, hyaluronidases and lipases to act synergistically each other enhancing functions and revitalizing the cells of the face. A significant difference was found in the care ratio between men and women, 1:14, that is, the women attended the consultation more requesting the placement of this treatment. Conclusion: The use of enzymes provides great benefits to increase skin permeability, increases lymphatic drainage, reduces fibrous septa of cellulite, sagging and fat, increases blood flow and rejuvenates the general appearance. So, it is proposed as an effective treatment to reduce expression lines.
\end{abstract}

Key words: Enzymes, treatment, collagenase, hyaluronidases and lipases
ZR: Instituto de Biomedicina "Dr. Jacinto Convit". Adjunto del Servicio de Dermatología. Hospital Vargas, CaracasVenezuela. 


\section{RESUMO}

ZR: Instituto de Biomedicina "Dr. Jacinto Convit". Adjunto del Servicio de Dermatología. Hospital Vargas, CaracasVenezuela.
Introdução: O tratamento enzimático é uma alternativa estética minimamente invasiva para melhorar a aparência facial e diminuir as linhas de expressão. Objetivo: Determinar o uso das enzimas hialuronidase, colagenase e lipase como tratamento enzimático dermatológico para linhas de expressão facial. Materiais e métodos: Estudo de campo em perspectiva, população de 457 pacientes que compareceram à consulta dermatológica entre 2013 e 2018 para tratamento enzimático. O instrumento de coleta de dados foi a folha de registros e a fonte documental foram os registros médicos. O método estatístico foi descritivo, as informações são apresentadas em tabelas e gráficos. Resultados: A idade média dos pacientes foi de 45,2 $\pm 10,1$ anos, $40,9 \%$ receberam 2 kits de enzimas com os 3 componentes básicos de colagenase, hialuronidases e lipases. Foi encontrada diferença significativa de 1:14 na relação de atenção entre homens e mulheres, ou seja, as mulheres compareceram mais frequentemente as consultas para a colocação desse tratamento do que aos homes. Conclusão: $O$ tratamento enzimático oferece benefícios ao aumentar a permeabilidade dérmica, aumenta o fluxo sanguíneo e a drenagem linfática, reduz os septos fibrosos da celulite, flacidez, adiposidade e rejuvenesce a aparência geral. Por isso, é proposto como um tratamento eficaz para diminuir as linhas de expressão.

Palabras clave: Enzimas, tratamento, colagenasa, hialuronidasas; lipasas

\section{INTRODUCCIÓN}

$\mathrm{L}$ as exigencias de las personas en cuanto a tratamientos estéticos están dirigidas a mantener una apariencia más joven y saludable tratando de detener los perjuicios ocasionados por el ambiente y el paso de los años a través de métodos pocos invasivos que les permitan mantener su cotidianidad con la obtención de resultados satisfactorios. Estos requerimientos han incrementado la utilización de productos como las enzimas, por sus resultados favorables en pocas sesiones al disminuir las líneas de expresión con inyección del producto en las zonas específicas

Las células producen muchas enzimas, con características y funciones bien definidas y variadas, puesto que hay cientos de transformaciones químicas que deben ocurrir para mantener la homeostasis del organismo y cubrir las exigencias, actúan como catalizadores "aceleradores" de reacciones biológicas intracelulares.
Las enzimas se pueden extraer del organismo para su transformación y purificación para aplicaciones en diferentes áreas, que van desde la preparación de alimentos y bebidas, hasta la síntesis de fármacos y otros compuestos importantes en la industria química (1).

El tratamiento con enzimas representa una alternativa estética mínimamente invasiva. La lipasa favorece la reducción de la capa grasa hipertrófica, la colágenasa relaja las fibras de colágeno con un efecto alisador y reafirmante de la piel y la hialunoridasa incrementa la permeabilidad dérmica, aumenta el drenaje linfático y el flujo sanguíneo mejorando la penetración de los productos enzimáticos y otros en la piel.

La matriz extracelular de la piel (ECM) cumple su función en la regulación de diversos mecanismos celulares, incluida la proliferación, la adhesión, la migración y la regulación génica. Los componentes principales de la ECM son las proteínas fibrosas colágeno y elastina, así como los proteoglicanos (PG) a los que se unen las 
cadenas

características

de

glicosaminoglicanos (GAG).

El GAG más común en la dermis es el ácido hialurónico (también llamado hialuronano). El hialuronano (HA) es un disacárido de glucosaminoglucano lineal compuesto de unidades alternas de $\mathrm{N}$ aceteil- D -glucosamina YD-glucurónico a través de enlaces glucosídicos $\beta$-1.4 y $\beta$-1.3 alternos. Es una sustancia viscosa mucopolisacárido componente esencial de la matriz extracelular responsable de mantener la adhesión celular actúa de manera temporal aumentando la permeabilidad y absorción del tejido (2).

Al ser extremadamente hidrofílico, él HA tiene una alta capacidad de hidratación $\mathrm{y}$, por lo tanto, contribuye a las propiedades viscoelásticas de la piel, su contenido disminuye con la edad, ocasionando pérdida de humedad y laxitud de la piel, ambos rasgos característicos del envejecimiento de la piel $(2,3)$.

Las hialuronidasas (Hyals) son clases de enzimas que degradan predominantemente el hialuronano (HA) (4). Son enzimas endoglicosidasas capaces de liberar oligosacáridos de una glicoproteína y pueden despolimerizar el HA, lo que lleva a su degradación al hidrolizar los disacáridos en enlaces hexosaminídicos $\beta$ - 1 a través de $\beta$-4 (5).

Existen varias fuentes de hialuronidasa, y generalmente se dividen en tres subgrupos: mamíferos; anquilostoma o sanguijuela y microbios y la hialuronidasa humana recombinante. Se requiere para su efecto un número bajo de unidades obteniendo resultados inmediatos con una vida media de dos minutos y una duración de acción de 24 a 48 horas (6). Cuando se aplica como adyuvante, la hialuronidasa mejora la capacidad de difusión y la biodisponibilidad de los medicamentos inyectados facilitando su absorción en los tejidos (3).
Las lipasas (glicerol-éster hidrolasas; EC 3.1.1.3) son enzimas que catalizan la hidrólisis de los enlaces éster presentes en los acilgliceroles in vivo. Son enzimas termoestables de bajo peso molecular, con una potente actividad lipolitica, son éster hidrolasas carboxílicas que rompen los enlaces éster de los acilglicéridos mediante la adición de una molécula de agua, dando lugar a ácidos grasos libres y glicerol, es decir actúan catalizando la separación hidrolítica de ácidos grasos de cadena larga y glicerol en un entorno que no sea agua, por lo que se explica su acción en la disminución de la grasa localizada en zonas como abdomen, muslos, flancos, papada, entre otras (7). La lipasa en dermatología disuelve los triglicéridos, reduce la capa grasa hipertrófica movilizando la grasa localizada.

La colágenasa son moléculas que participan en una gran cantidad de procesos del organismo su función es romper los enlaces peptídicos del colágeno e intervenir en su reordenamiento. Es una enzima con una alta capacidad fibrinolítica que actúa disolviendo las fibras de colágeno alrededor de los adipocitos presentes en los nódulos celulíticos mejorando el aspecto de la piel (8).

En dermatología el uso de la colágena es variado; en quemaduras y úlceras, para eliminar tejido de cicatrices y en trasplante de órganos donde ayuda a la reparación de la dermis y favorecen la etapa de granulación y reepitelización, en cicatrices hipertróficas posterior a quemaduras, acné o cirugías. Su combinación con láser da buenos resultados: relaja las fibras de colágeno, alisa la piel, reduce la llamada "piel de naranja" y degrada el colágeno viejo con la consecuente producción de colágeno nuevo.

Entre los efectos indeseables de la colagenasa más relevantes se destacan principalmente secundarios a la inyección (hematomas, dolor, ardor) en algunos 
casos es posible que se presente el mismo día o al día siguiente malestar general, escalofríos y fiebre.

El objetivo del trabajo fue determinar el uso de las enzimas hialuronidasa, colagenasa y lipasa como tratamiento enzimático dermatológico regenerador para las líneas de expresión.

\section{MATERIALES Y MÉTODOS}

$\mathrm{S}$ e realizó un estudio de descriptivo, de campo, prospectivo a una población conformada por 457 pacientes que acudieron a la consulta dermatológica de UNIMEL entre los años 2013 y 2018 para ser tratados con enzimas. El instrumento de recolección de datos fue la hoja de registro y la fuente la historia. Se utilizó estadística descriptiva. Se solicita el consentimiento informado del paciente. Se incluyeron todos los pacientes que acudieron a la consulta de la Unidad Medico Estética Laser UNIMEL y que fueron tratados con las enzimas de hialunoridasas, colagenasa y lipasa

\section{RESULTADOS Y DISCUSIÓN}

$\mathrm{L}$ a población de pacientes total tratados con enzimas fue de 457 personas a quienes se les colocó tratamiento con las enzimas de hialunoridasas, colagenasa y lipasa. Esta población constituida por 427 mujeres y 30 hombres quienes representan el 93,4\% y 6,6\% respectivamente con una relación promedio de 1 hombre por cada 14 mujeres atendidas. (Tabla 1 ).

Los tratamientos dermatológicos están diseñados para los requerimientos individuales de las personas indistintamente del sexo, por lo general son más solicitados por la población femenina.

En cuanto a la edad no existe una limitante para la realización de dichos tratamientos, todo es acorde a la clasificación y cuidados que reciba la piel lo que ocasiona daños en mayor o menor cuantía para la aparición de las líneas de expresión.

Tabla 1. Descripción del total de tratamientos con Enzimas aplicados a pacientes en el centro de atención médica UNIMEL.

\begin{tabular}{lll}
\hline Variables & $\mathbf{n}$ & $\mathbf{\%}$ \\
\hline Tratamientos con Enzimas & 457 & \\
Sexo: & & 6,6 \\
$\quad$ Masculino & 40 & 93,4 \\
Femenino & $1: 14$ & \\
$\quad$ Relación Hombre/Mujeres & & \\
Edad General: & $45,2 \pm 10,1$ \\
$\quad$ Promedio (años \pm DE) & 36 & \\
Edad más frecuente & & \\
Edad Mujeres: & $44,8 \pm 9,7$ & \\
$\quad$ Promedio (años \pm DE) & 36 & \\
$\quad$ Edad más frecuente &
\end{tabular}




\begin{tabular}{lll}
\hline Variables & n & \% \\
\hline Edad Hombres: & & \\
Promedio (años \pm DE) & $50,8 \pm 13,2$ & \\
Edad más frecuente & 59 & \\
Número de kits & 156 & 34,1 \\
1 kit & 187 & 40,9 \\
2 kits & 64 & 14,0 \\
3 kits & 34 & 7,4 \\
4 kits & 4 & 0,9 \\
5 kits & 6 & 1,3 \\
6 kits & 4 & 0,9 \\
7 kits & 1 & 0,2 \\
8 kits & 1 & 0,2 \\
15 kits & & \\
\hline
\end{tabular}

Fuente: Historia clínica

Cada kit de enzima incluye a la hialuronidasa, colagenasa y lipasa, se realiza una evaluación exhaustiva para determinar las necesidades reales de cada persona y si realmente este tratamiento solicitado es el más recomendable para su piel y la afección cutánea presentada, una vez realizado esto y se determina la cantidad de kit a usar el cual por lo general varía entre 1-3 kits como se le colocó al $88,52 \%$ de la población consultad, con una distribución 1 kit a 147 personas 34,43\%,
2 kits a 175 mujeres lo que represento el $40,98 \%$ y 3 kits a 56 mujeres para un porcentaje de 13,11\% . Existen casos que, dadas la magnitud de la afección en cuanto a su profundidad, la extensión o cantidad de zonas requieren la colocación de más kits, hasta ahora la mayor cantidad requerida fue de 15 kits a una sola persona lo que representa un $0,23 \%$, esto para el sexo femenino, como se muestra en la tabla 2 .

Tabla 2. Resumen general del número de kits de enzimas aplicados a pacientes femeninos

\begin{tabular}{lll}
\hline Num de kits & Frequency & Percent \\
\hline 1 kit & 147 & $34,43 \%$ \\
2 kits & 175 & $40,98 \%$ \\
3 kits & 56 & $13,11 \%$ \\
4 kits & 33 & $7,73 \%$ \\
5 kits & 4 & $0,94 \%$ \\
6 kits & 6 & $1,41 \%$ \\
7 kits & 4 & $0,94 \%$ \\
8 kits & 1 & $0,23 \%$ \\
15 kits & 1 & $0,23 \%$ \\
\hline Total & $\mathbf{4 2 7}$ & $\mathbf{1 0 0 , 0 0 \%}$ \\
\hline
\end{tabular}

Fuente: Historia clínica 
La tabla 3 muestra la cantidad de kits de enzimas utilizados con los pacientes de sexo masculino, los cuales fueron un total de 30 casos equivalente a un $6,6 \%$ de los pacientes en total tratados con enzimas. $\mathrm{Al}$ igual que en el caso femenino, la mayor cantidad de kits utilizados varia de 1 a 3 kits por persona, que en este caso representa un total de $96,67 \%$ de la totalidad, distribuidos en un $30 \%$ (9 personas) en recibir un kit, 40\% (12 personas) a quienes se les colocaron dos kits y 8 personas equivalentes a un 26,67\% a quienes se les colocaron 3 kits, una sola persona requirió de la utilización de 4 kits de enzimas.

Tabla 3. Resumen general del número de kits de enzimas aplicados a pacientes masculinos

\begin{tabular}{lll}
\hline Num de kits & Frequency & Percent \\
\hline 1 kit & 9 & $30,00 \%$ \\
2 kits & 12 & $40,00 \%$ \\
3 kits & 8 & $26,67 \%$ \\
4 kits & 1 & $3,33 \%$ \\
\hline Total & $\mathbf{3 0}$ & $\mathbf{1 0 0 , 0 0 \%}$
\end{tabular}

Fuente: Historia clínica

Los usos del tratamiento dermatológico con enzimas son variados van desde lo reconstructivo para mejorar cicatrices posterior a quemaduras hasta lo estético aplicadas para aportar firmeza y rejuvenecimiento a la piel por lo que no existe una población demandante definida, reflejo de esto se puede visualizar en el gráfico 1 donde la distribución entre los grupos etarios la cual es prácticamente equitativa entre los rangos de edades de 31 a 40 , de 41 a 50 y de 51 a 60 años edad cada con un $30 \%$, mientras que los grupos etarios de 20 a 30 años y los mayores de $60 \%$ representan cada uno solo un $5 \%$ del total de la población a quienes se les aplicó tratamiento dermatológico con enzimas.

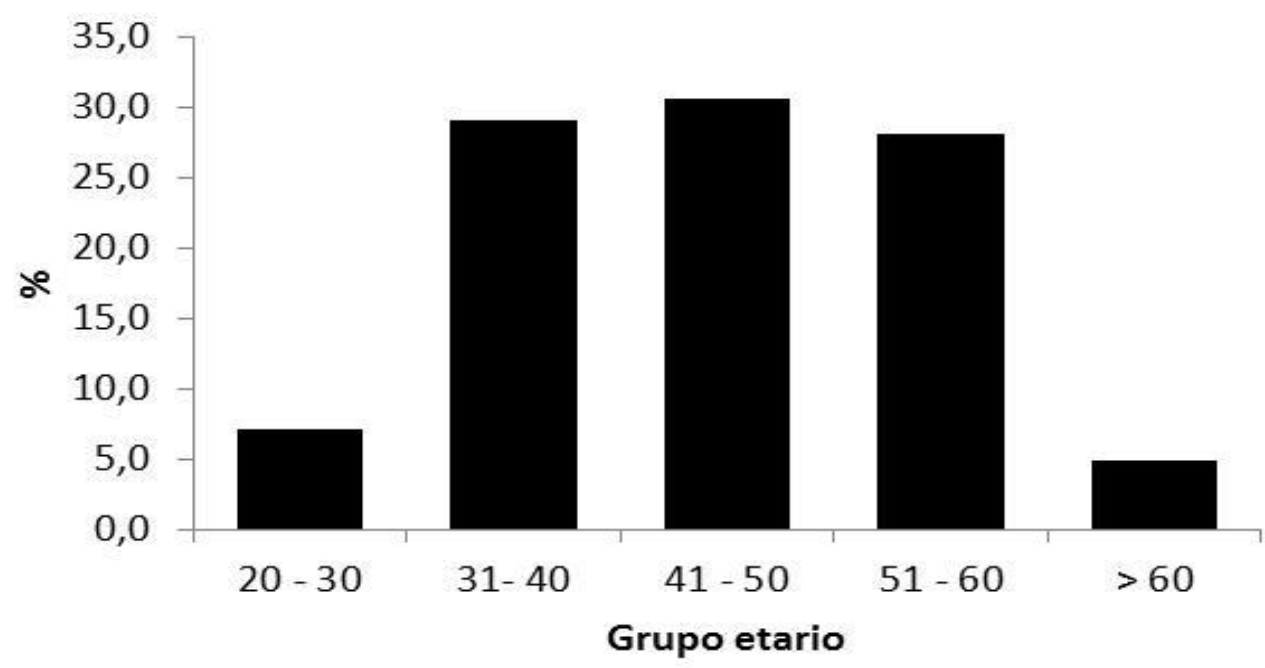

Gráfico 1. Grupo etario de tratamientos con Radiofrecuencia con Agujas. Fuente: Historia clínica 


\section{Discusión}

La preocupación de muchas personas a medida que avanza el tiempo es disminuir las líneas de expresión que se acentúan con el paso de los años. En ese sentido se observó que la población consultante tenía una edad frecuente de 36 años de edad con un promedio de edad de $45,2 \pm 10,1$ años.

Actualmente existen tratamientos con fines estéticos que usan la combinación de enzimas para obtener efectos apropiados en la reestructuración por estratos de la piel, con resultados aparentemente efectivos. Las enzimas que se unen con este fin son tres hialuronidasas, colágenasa y lipasa (9).

Las enzimas son responsables de desacoplar moléculas inactivas complejas y transformarlas en moléculas más simples y, a menudo, más activas (10).

Las lipasas debido a su capacidad sobresaliente de metabolizar los lípidos han encontrado su camino en formulaciones que incluyen productos para la limpieza de la nariz, máscaras de maquillaje y cuidado del cabello. Las hialuronidasas, otro grupo de enzimas, han tenido más éxito en cirugías cosméticas como un componente activo en los rellenos dérmicos. Las enzimas son agentes activos naturales para productos de cuidado personal específicos que pertenecen a los llamados "cosméticos funcionales" (10).

El ácido hialurónico, es el relleno más usado en la medicina estética y para el tratamiento de complicaciones asociadas. El AH incrementa la síntesis de colágeno a través de los fibroblastos, y favorece la retención hídrica en la piel (11).

Cuando se mezclan la hialuronidasa, la lipasa y a colagenasa se originan metabolitos intermediarios, en el interior de la célula, promoviendo básicamente una cascada de eventos reestructurativos en pieles senescentes, con presencia de líneas de expresión y flacidez, causando remodelación en pieles expuestas a peso excesivo producto de la lipomatosis (9).

Más allá de los tratamientos dermatológicos estas enzimas tienen múltiples usos y beneficios por ejemplo la hialuronidasa se ha utilizado como un adyuvante local para aumentar la capacidad de difusión de los anestésicos locales, aumentando la eficacia analgésica y el área anestesiada, particularmente en los primeros minutos después de la inyección, lo que resulta en una disminución del dolor intra y postoperatorio, además la hialuronidasa se ha utilizado con éxito en cirugía oftálmica (2).

\section{CONCLUSIONES}

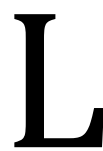
as personas tratan de cuidar la piel a través de procedimientos estéticos menos invasivos con tiempos de recuperación más rápido y mejoras significativas, en este sentido las proteínas recombinantes pueden ser utilizadas como agentes terapéuticos en el tratamiento de enfermedades, y ahora en la remodelación de pieles envejecidas

Evitar el efecto progresivo del envejecimiento es el principal objetivo en dermatología estética, donde se destaca principalmente la flacidez cutánea con pérdida del contorno facial por disminución del reborde óseo, es posible recuperar firmeza a través de la aplicación de enzimas.

Las enzimas (Hialuronidasa, Colagénasa, Lipasa) ofrecen gran versatilidad en sus usos, representan una excelente opción en tratamiento dermatológico (cicatrices, queloides, morfea, quemaduras) y estéticos (adiposidades localizadas, celulitis, flacidez, estrías, papada). Además de ser muy solicitadas por ser un tratamiento prácticamente indoloro, que no requiere tiempo de recuperación. El uso de enzimas 
ha demostrado ser un tratamiento de elección para disminuir las líneas de expresión y con resultados efectivamente comprobados.

- Conflicto de intereses. Ninguno declarado por la autora

- Financiación. Ninguna declarada por la autora

- Agradecimiento: Ninguno manifestado por la autora

- Investigación realizada considerando los tratados bioéticos

\section{REFERENCIAS}

1.- Ramírez J, Ayala M. Enzimas: ¿qué son y cómo funcionan? 2014; 15(12):16071609. (Consultado el 20-03-2019); Disponible en http://www.revista.unam.mx/vol.15/num 12/art91/\#

2.- Buhren B, Schrumpf H, Hoff N, Bölke E, Hilton S, Gerber P. Hialuronidasa: desde aplicaciones clínicas hasta mecanismos moleculares y celulares. Eur J Med Res. 2016; 21:(5)

3.- Vázquez H, Sigall D. Hialuronidasa: aplicaciones dermatológicas Hyaluronidase in dermatology. 2011; 9(4) 292-294 (Consultado 23 de marzo 2018); Disponible en: https://www.medigraphic.com/pdfs/cos metica/dcm-2011/dcm114i.pdf

4.- Klotz L, Balassiano A, Souza B, Bravo F. Hyaluronidase: a necessity for any dermatologist applying injectable hyaluronic acid. Surg Cosmet Dermatol
2014; 6(4)338-43, (Consultado 15 marzo 2018)

5.- Stern R, Jedrzejas M. Las hialuronidasas: su genómica, estructuras y mecanismos de acción. Chem Rev. 2006; 106(3):818-839. (Consultado 16(mayo 2017)

6.- King M, Convery C, Davies E. Guía de este mes: El uso de hialuronidasa en la práctica estética J Clin Aesthet Dermatol. 2018; 11(6):E61-E68. (Consultado 15 marzo 2018)

7.- González-Bacerio J. Rodríguez J. y Del Monte A. Las lipasas: enzimas con potencial para el desarrollo de biocatalizadores inmovilizados por adsorción interfacial. Rev. Colomb. Biotecnol. 2010; 12(1):124-140 (Consultado 14 marzo 2018)

8.- Fierro-Arias L, Campos-Cornejo N, Contreras-Ruiz J, Espinosa-Maceda S, López-Gehrke I, Márquez-Cárdenas R, et al. Productos enzimáticos (hialuronidasa, colagenasa y lipasa) y su uso en Dermatología. Dermatol Rev Mex. 2017; 61(3):206-219. (Consultado 18 mayo 2018)

9.-Velazco G. Enzimas recombinantes ficción o realidad. Acta Bioclinica. 2019. 9(17): 2-3. (Consultado octubre 2019)

10.- Sunar K, Kumar U, Deshmukh S. Recent Applications of Enzymes in Personal Care Products. (Consultado el 15 de marzo de 2019). DOI: 10.1016 / B9780-12-802392-1.00012-5

11.- Brazón A, Martínez C, Pirela F, San Luis S, Giansante E. Hialuronidasa. Uso e indicaciones en dermatología. Dermatol venez. 2019; 57(2). (Consultado 15 de noviembre 2019) 